\title{
PROBLEMATIKA KURIKULUM 2013 PENDIDIKAN AGAMA ISLAM \\ DAN KEPEMIMPINAN INSTRUKSIONAL \\ KEPALA MADRASAH IDTIBA'TYAH KOTA PASURUAN
}

\author{
Wachyudi Achmad \\ STIT Muhammadiyah Bangil \\ awachyudi330@gmail.com
}

\begin{abstract}
The curriculum has an important role in the education process. And it should play a role and be anticipatory and adaptive to changes and advances in science and technology. Curriculum and learning are two important aspects of educational activities. Both discuss what and how education should be carried out and blend with local wisdom. Therefore, along with changes and developments in the curriculum from time to time an educator must be able to understand and implement it well. In order to be in accordance with what is expected, there needs to be a discussion of curriculum development from Kurikum 1994, Competency Based Curriculum (KBK) 2004, Education Unit Level Curriculum (KTSP), and Curriculum 2013 until now. This paper tries to provide one solution to the problems of the 2013 curriculum implementation. Instructional leadership of the Pasuruan City Islamic Senior High School principals is recommended to be one solution to the effectiveness of the 2013 curriculum implementation. Instructional Leadership is the leadership of the madrasa head who prioritizes teaching and learning in leadership. The head of the madrasa in favor of academics, instructional leadership is believed to be able to solve the problems of the implementation of the 2013 curriculum. Prioritizing the involvement of the headmaster in orientation and training for 2013 curriculum implementation is recommended.
\end{abstract}

Keywords: Problematic curriculum 2013, Instructional Leadership, Pasuruan Madrasah Ibtidaiyah

\section{Pendahuluan}

Pendidikan di Indonesia sudah mengalami beberapa kali perubahan kurikulum. Menurut Suparlan kurikulum pertama Indonesia adalah Rencana Pelajaran 1947. Ketika itu, istilah kurikulum belum digunakan. Kemudian, Rencana Pelajaran 1947 ini dirubah menjadi Rencana Pelajaran 1950. Selanjutnya diganti dengan Rencana Pelajaran 1958. Rencana pelajaran ini kemudian direvisi menjadi Rencana Pelajaran 1964. Setelah 
itu rencana pelajaran ini diganti menjadi Kurikulum 1968. Sejak inilah istilah rencana pelajaran yang sudah digunakan selama bertahun-tahun berganti nama menjadi kurikulum. Kemudian, kurikulum ini dirubah lagi menjadi Kurikulum 1975. Selanjutnya, Kurikulum 1984, Kurikulum 1994, Kurikulum Berbasis Kompetensi (KBK) 2004, Kurikulum Tingkat Satuan Pendidikan (KTSP) 2006 dan terakhir kurikulum 2013 (Suparlan, 2012).

Perubahan yang terakhir ini adalah amanat perubahan metodologi pembelajaran dan penataan kurikulum dalam RPJMN (Rencana Pembangunan Jangka Menengah Nasional). Selain itu, perubahan ini dilakukan sebagai penyempurnaan kurikulum dengan metode pembelajaran aktif berdasarkan nilai-nilai budaya bangsa untuk membentuk manusia Indonesia yang berdaya saing dan berkarakter sesuai Instruksi Presiden Nomor 1 Tahun 2010. Perubahan atas dasar ini didukung oleh teori pengembangan kurikulum, antara lain, dikemukakan oleh Hamalik bahwa kemajuan di bidang ilmu pengetahuan dan teknologi memberikan dampak terhadap sistem pengajaran, sehingga pembelajaran mengalihkan pendekatannya dari pendekatan tradisional ke pendekatan mutakhir (Hamalik, 2012).

Perubahan kurikulum juga merupakan akibat dari perkembangan masyarakat dan kesenjangan dalam mendapatkan hak pendidikan yang layak. Kita tidak ingin membangun generasi yang terpisah dengan perkembangan masyarakatnya. Kita mendidik generasi yang akan hidup di zaman yang berbeda dengan kita. Kita mendewasakan mereka melalui pendidikan yang tidak usang yang muatannya tertuang di dalam kurikulum (Sukmadinata, 2008). Perubahan kurikulum pendidikan suatu negara biasanya diprakarsai oleh kementerian pendidikan. Menteri Pendidikan dan Kebudayaan, Muhammad Nuh mengatakan akan konsisten dan terus maju dengan rencana implementasi kurikulum 2013 meskipun kritik dan protes datang bertubi-tubi dari berbagai kalangan. Umumnya kritik-kritik tersebut datang dari guru, edukator dan pemerhati pendidikan. 
Menurut Muhammad Nuh, mutu pendidikan Indonesia akan terus memburuk kalau kurikulum baru ini tidak dilaksanakan. Dengan mengatakan "masa depan negeri ini tergantung kepada kurikulum 2013" (Saragih, 2013). Namun banyak kalangan yang menyebutkan bahwa diimplementasikan kurikulum 2013 ini dianggap terlalu tergesa-gesa dalam pelaksanaannya sehingga menuai banyak kritikan karena dianggap memiliki segudang masalah. Tulisan ini bertujuan untuk memaparkan problematika kurikulum 2013 dan mencoba memberi alternatif solusi bagi suksesnya implementasi kurikulum 2013, melalui Kepemimpinan Instruksional (Instructional Leadership) sebagai pelaku dan bertanggung jawab dilevel paling bawah.

\section{Masalah-masalah Kurikulum 2013 PAI}

Anggaran yang digunakan untuk perubahan kurikulum 2013 tidaklah sedikit nilai rupiahnya cukup fantastis yaitu sebesar 2,49 T, akan tetapi dalam pembahasan kali ini tidaklah penting nilai nominalnya, tetapi yang perlu dipahami adalah kritikan-kritikan dalam proses penyempurnaan dari para pakar pendidikan tentang dampak yang akan muncul di kemudian hari, karena kurikulum itu dapat dirasakan hasilnya melalui proses yang panjang. Kritikan yang dimaksud penulis semisal, membuang sains dan menggantikannya dengan pendidikan kewarganegaraan dan pelajaran agama. Jadi, kurikulum baru ini lebih banyak muatan pendidikan kebangsaan dan agama, sedangkan sains atau IPA akan digabung ke dalam dua mata pelajaran tersebut. Menurut Menteri Pendidikan dan Kebudayaan, Muhammad Nuh, yang dikutip oleh berbagai media massa, kurang elok apabila mengintegrasikan pendidikan kebangsaan dan pendidikan agama dengan pelajaran kimia dan ini akan membuat anak menjadi lebih kreatif. Muhammad Nuh juga mempertahankan keputusan menteri untuk menambah jam pelajaran agama dengan harapan penambahan dua jam pelajaran agama akan membantu program pembasmian teroris dan tawuran antar pelajar. Muhammad Nuh 
berkeyakinan bahwa gerakan teroris tidak dipicu oleh lamanya jam pelajaran agama di sekolah (Rosyidah \& Utomo, 2014). Justru aksi terorisme yang semakin meningkat di Indonesia, menurutnya, karena tidak lengkapnya pendidikan agama. Oleh karena itu, kita perlu menambah jam pelajaran agama. Pertanyaannya adalah, mengapa agama selalu dijadikan alasan yang mendasar dalam penangulangan chaos-nya dunia pendidikan?

Namun demikian, adapula kebijakan yang diambil dianggap kontra produktif. Sebagai contoh salah satunya adalah bidang pendidikan. Ketika pemerintah yang lama mengeluarkan kurikulum baru yang diterbitkan di akhir masa jabatannya, yang terjadi adalah kekagetan nasional. Kaget karena konsep yang diusung berbeda dengan kurikulum yang selama ini telah dilakukan, yang mulai menjadi zona nyaman bagi sebgian besar pendidik di Indonesia. Adanya formulasi baru dalam pembelajaran, yang mengusik zona nyaman inilah yang menimbulkan pertentangan di sana sini. Apalagi diperkuat dengan kelompok ad hoc yang saat itu tidak masuk dalam gerbong penentu kebujakan kurikulum, yang selama ini berusaha untuk memaksakan kehendaknya melalui kritik dan penolakan di berbagai tempat. Kurikulum 2013 ini diberlakukan secara bertahap mulai Tahun Pelajaran 2013-2014 melalui pelaksanaan terbatas, khususnya bagi sekolah-sekolah yang sudah siap melaksanakannya. Pada Tahun Pelajaran 2013/2014, Kurikulum 2013 dilaksanakan secara terbatas untuk Kelas I dan IV Sekolah Dasar/Madrasah Ibtidaiyah (SD/MI), Kelas VII Sekolah Menengah Pertama/Madrasah Tsanawiyah (SMP/ MTs), dan Kelas X Sekolah Menengah Atas/ Sekolah Menengah Kejuruan/Madrasah Aliyah (SMA/SMK/MA/MAK). Pada Tahun Pelajaran 2014/2015 diharapkan Kurikulum 2013 telah dilaksanakan di seluruh kelas I sampai dengan Kelas XII (Halimah, 2015).

Menteri pendidikan nasional yang baru mengeluarkan peraturan untuk menunda pelaksanaan kurikulum 2013 sampai masa jabatannya 
selesai. Kebijakan ini dituangkan dalam Permendikbud Nomor 160 tahun 2014. Kebijakan tersebut pada pasal 4 berbunyi "Satuan pendidikan dasar dan pendidikan menengah dapat melaksanakan Kurikulum Tahun 2006 paling lama sampai dengan tahun pelajaran2019/2020". Keputusan ini dianggap sebagai keputusan banci bagi sebagian orang. Bagaimana tidak, kebijakan ini menggantung harapan pelaku pendidikan dan ini adalah masa akhir jabatan menteri selama 5 tahun. Pasal itu tidak menyatakan lanjut, namun juga tidak dinyatakan berhenti. Hal yang lebih parah lagi adalah bahwa untuk memperkuat tekanan agar menunda pelaksanaan kurikulum 2013, menteri dalam negeri juga mengeluarkan peraturan yang 'memaksa' para guru dan sekolah untuk tidak melanjutkan implementasi kurikulum baru bila baru melaksanakan selama 1 semester. Hal ini bisa dilihat pada Surat Edaran Mendagri Nomor 423.5/154/sj. Bagaiman logika akademiknya kementerian dalam negeri mengeluarkan peraturan tentang implementasi kurikulum yang menjadi wilayah kementerian pendidikan dan kebudayaan?. Dimana letak nilai-nilai keadilannya dalam terapan kurikulum 2013 di lingkungan madrasah yang tidak menyeluruh?. Mengapa kemenag terkesan selalu lamban dalam memberlakukan kurikulum 2013?

Apabila kita menganalogikan kebijakan kurikulum sepaket dengan silabus yang dibuat pemerintah ini sebagai suatu produk pakaian yang berukuran sama, atau satu ukuran dengan mempertanyakan, Should one size fit all? Tentu saja pakaian yang dibuat dengan satu ukuran tidak bisa dipakai oleh semua orang, karena orang menggunakan ukuran pakaian yang berbeda-beda seperti ukuran $S, M, L, X L$ bahkan ukuran XXL. Menurutnya, paling tidak, terdapat tiga kelemahan yang dapat diasumsikan dengan kurikulum 2013, yaitu:

1. Perencana kurikulum telah salah mengidentifikasikan masalah, yaitu menganggap guru tidak sanggup merancang silabus sehingga 
menganggap obat mujarabnya adalah merancang kurikulum yang sama, satu ukuran, bersama dengan silabusnya untuk semua sekolah.

2. Seperti pakaian satu ukuran, kurikulum baru ini bisa cocok untuk satu sekolah tetapi belum tentu cocok untuk sekolah lainnya. Yang lebih mencemaskan lagi beberapa sekolah bisa terabaikan karena mereka memiliki masalah dan kebutuhan yang unik. Kurikulum yang mengasumsikan semua sekolah, fasilitas, guru dan siswa sama adalah kurang tepat.

3. Guru tidak dipercaya menyangkut kreativitas mereka dalam mengembangkan kurikulum berdasarkan kebutuhan kontekstual dan kebutuhan-kebutuhan unik di setiap daerah. Kurikulum 2013 diasumsikan bahwa guru akan disetir dari jarak jauh dengan menggunakan remote control universal yang disebut silabus. Sakhiyya juga mengutip Winston Churchill yang mengatakan bahwa "barang siapa yang gagal merencanakan berarti merencanakan kegagalan (Hidayatullah, 2016).

\section{Masalah Guru}

Kurikulum 2013, sebagaimana Menteri Pendidikan dan Kebudayaan telah jelaskan, merupakan perbaikan dari kurikulum 2004 dan 2006, yang merupakan kurikulum berbasis sekolah dan berbasis kompetensi. Namun, guru masih sedang mempelajari bagaimana melaksanakan kurikulum 2006. Sangat disesalkan, kebanyakan guru dan masyarakat umum tidak diinformasikan apa yang sebenarnya tidak beres dengan kurikulum 2006. Pemerintah seharusnya telah mempublikasikan data hasil evaluasi untuk mengidentifikasikan aspek mana kurikulum 2013 yang bermasalah. Data semacam itu akan membuat perubahan kurikulum lebih masuk akal. 
Selanjutnya, peleburan mata pelajaran di tingkat Sekolah Dasar juga menimbulkan masalah. peleburan tersebut akan menimbulkan masalah terutama terkait keberadaan guru. Ketika mata pelajaran dileburkan dan integrasikan, banyak guru yang sudah menjadi guru profesional kehilangan pekerjaan. Bahkan tidak bisa lagi menerima tunjangan profesi karena jam mengajarnya tidak cukup. Di samping itu, apa yang disebut pendekatan tematik integratif ini diakui banyak pihak sangat memberatkan guru. Begitu juga dengan pedoman kolaborasi kontekstual dan praktek yang tidak dirincikan dalam implementasi kurikulum 2013. Ini akan berpotensi merugikan siswa dan membingungkan guru.

\section{Masalah Lainnya}

Masalah kurikulum 2013 lainnya seperti multi tafsir juga menjadi hambatan dalam implementasi kurikulum 2013. Sebagai contoh, kurikulum 2013 menggunakan pendekatan saintifik dalam aktivitas pembalajaran dengan lima langkah pokok: Mengamati, Menanya, Mengumpulkan informasi (explorasi), Mengasosiasi (menggunakan pengetahuan) dan Mengkomunikasikan. Menyangkut langkah terakhir, "Mengkomunikasikan" telah menimbulkan interpretasi yang berbeda meskipun itu memang berbeda berdasarkan jenjang pendidikan. Ada yang menafsirkan "Mengkomunikasikan" sebagai menyampaikan atau mengkomunikasikan pengetahuannya setelah proses pembelajaran kepada orang lain atau teman sekelasnya baik secara lisan maupun tulisan. Namun, banyak juga yang menafsikan "Mengkomunikasikan" itu maksudnya siswa berjaringan, menggunakan internet untuk mencari lagi inquiry atau memperdalam pengetahuannya dan menggunakan fasilitas internet seperti email untuk berkomunikasi dengan ahli di bidang tertentu. kurikulum berkarakter di Indonesia karena siswa tidak mudah mendapatkan contoh tauladan yang bisa mereka tiru atau ikuti dari orang dewasa. Di kalangan orang dewasa 
terjadi penyelewengan, konspirasi, nepotisme dan korupsi yang semakin merajalela. Tidak terlihat secara jelas implementasi norma-norma hukum dan nilai-nilai agama dalam kehidupan sehari-hari.

Ada juga yang mempertanyakan kenapa Pendekatan Saintifik yang diterapkan. Sedangkan rekomendasi ahli psikolog pembelajaran adalah Konstruktivisme, karena Teori Konstruktivisme merupakan penyempurnaan dari teori-teori utama pembelajaran sebelumnya, Behaviorisme dan Kognitivisme. Bahkan, ada pihak yang mengkritik dengan sinis bahwa pendekatan yang digunakan merupakan Pendekatan Saintifik, tetapi kenapa sainsnya banyak dibuang.

Kepemimpinan Instruksional Kepala Madrasah Ibtidaiyah Kota Pasuruan Kepemimpinan Instruksional atau Pemimpin Pengajaran berbeda dari tugas kepala madrasah sebagai pengatur atau manejer dalam banyak hal. Para kepala madrasah yang membanggakan diri mereka sebagai manejer, biasanya terlalu fokus dengan tugas-tugas administratif yang ketat dibandingkan dengan kepala madrasah yang berperan sebagai Pemimpin Instruksional. Peran yang terakhir melibatkan penentuan tujuan-tujuan yang jelas, pengalokasian sumber daya untuk pengajaran, pengurusan kurikulum, pemantauan rencana pembelajaran (lesson plans), dan evaluasi para guru. Singkat kata, kepemimpinan instruksional adalah aksi-aksi yang seorang kepala madrasah lakukan, atau delegasikan kepada orang lain, untuk meningkatkan pembelajaran siswa (Flath, 1989). Sebaliknya, Pemimpin Instruksional memprioritas atau mengutamakan kualitas pengajaran sebagai prioritas utama madrasah dan berusaha untuk mewujudkan visi itu menjadi kenyataan. Intinya seluruh kesibukan seorang kepala madrasah diperuntukkan mempengaruhi kegiatan akademik madrasah yang berkaitan dengan madrasah. 
Kepala Madrasah dituntut untuk mengaitkan antara komponen satu dengan lainnya menjadi suatu kesatuan yang kompak dalam mencapai tujuan pendidikan yang diharapkan, sehingga madrasah mampu mewujudkan tujuan ideal madrasah yaitu: pertama, sebagai wahana untuk memperdalam ilmu keislaman serta membina roh dan praktik hidup keislaman; kedua, memperjelas dan memperkokoh keberadaan madrasah agar dapat memenuhi bahkan melebihi standar nasional pendidikan; dan ketiga, mampu merespon tuntutan-tuntutan masa depan dalam arti sanggup melahirkan manusia yang memiliki kesiapan memasuki era globalisasi maupun era reformasi. Perwujudan ciri kepemimpinan dalam langkah-langkah kepemimpinan tersebut tampak dalam model kepemimpinan instruksional dan transformasional yang diperlukan untuk pengembangan lembaga pendidikan islam. Kepemimpinan instruksional diimplementasikan karena Kepala Madrasah adalah pemimpin di lembaga pendidikan dan kepemimpinan transformasional diterapkan karena Kepala Madarasah bertujuan untuk mentransformasi lembaga pendidikan yang dipimpinnya.

\section{Penutup}

Menyadari bahwa pendidikan bukan merupakan proyek main-main, sangat diharapkan keseriusan dari aparat Kemenag yang diserahi wewenang untuk mengelola pendidikan agar dapat berpikir dan bertindak lebih cerdas dalam membuat kebijakan tentang pendidikan. Kesalahan dalam pengambilan keputrsan akan berdampak terhadap generasi mendatang. Dampak ini memang tidak atau belum terasa dalam waktu 1 atau 7 tahun, namun beberapa tahun mendatang, namun jika sudah mulai menunjukkan hasilnya, tidak cukup waktu 1 generasi memperbaikinya.

Berdasarkan konsep Kepemimpinan Instruksional, di samping merumuskan dan mensosialisasikan visi-misi sekolah, pemimpin instruksional hars selalu concern dengan kurikulum. Kepala sekolah semacam ini selalu mengkoordinasikan kurikulum, mensupervisi dan 
mengevaluasi kurikulum, dan memonitor kemajuan siswa. Pemimpin Instruksional juga selalu fokus pada penciptaan iklim pembelajaran sesama guru. Oleh karena itu, kepala sekolah terutama yang memposisikan diri sebagai Instructional Leader akan memainkan peran yang sangat menentukan dalam menyukseskan penerapan kurikulum 2013. Kepala sekolah dapat mengintervensi pemberlakuan kurikulum 2013 melalui pengelolaan kurikulum dan program pengembangan profesi guru di sekolah.

\section{DAFTAR PUSTAKA}

Halimah, S. 2015. Analisis pemahaman dan kesiapan guru mengimplementasikan kurikulum 2013.

Hamalik. 2012. Kurikulum dan pembelajaran. Jakarta: Bumi Aksara.

Hidayatullah, U. S. 2016. Tanggung Jawab Negara Terhadap Pendidikan Agama Islam. PPIM UIN Jakarta, (September), 1-8.

Saragih, Bagus. 2013. Future of Indonesia depends on new curriculum. The Jakarta Post, p.4 (National).

Rosyidah, I., \& Utomo, D. 1997. Gender dalam Buku-buku Pendidikan Agama Islam. Australian National University, 4(4).

Sukmadinata. 2008. Pengembangan Kurikulum: Teori dan Praktek (I). Bandung: Rosda Karya.

Suparlan. 2012. jawab pengembangan kurikulum \& materi pembelajaran (I). Jakarta: Bumi Aksara. 